\title{
Antimicrobial Activity of AgNPs Synthesized Via Green Approach by Using Flowers of Bistortamacrophylla herb of Tungnath Himalaya Region
}

\author{
Ankit Singh Bartwal ${ }^{1} \cdot$ Sumit Ringwal $^{1} \cdot$ Satish Chandra Sati ${ }^{*}$ \\ ${ }^{1}$ Department of Chemistry, HNB Garhwal University (A Central University) Srinagar Garhwal, Uttarakhand, India- \\ 246174
}

*Corresponding Author Email id: sati_2009@rediffmail.com

Received: 02.04.2021; Revised: 02.05.2021; Accepted: 12.05.2021

(OSociety for Himalayan Action Research and Development

\begin{abstract}
Green synthesis of nano structured materials isan emerging field for the researchers working in the field of chemical, physical, life sciences, engineering and medical sciences, for the welfare of society.In the present study green synthesis of silver nanoparticles (AgNPs)was performed by using flowers of Bistorta macrophylla, a medicinal herb of polygonaceae family of Garhwal Himalayas. For green synthesis of AgNPs, the aqueous flowers extract and the aqueous solution of $\mathrm{AgNO}_{3}$ (of 5 milli molar concentration) were well mixed in ratios of 1:9.The metal ion present in the solution reduced $\mathrm{Ag}^{+1}$ to $\mathrm{Ag}^{0}$ within three to four days, which was characterized by color change observation, UV, SEM-EDX, XRD, TEM etc. The absorption maxima of AgNPs of Bistorta macrophylla flowers (BMF) was obtained in the range of $451-454 \mathrm{~nm}$ for $5 \mathrm{mM}$ concentration of $\mathrm{AgNO}_{3}$, and the SEM images revealed that the average clustersize of synthesized $\mathrm{Ag}$ nanoparticles from $5 \mathrm{BMF}_{1: 9}$ ranges from $20 \mu \mathrm{m}-23 \mu \mathrm{m}$, while the EDX analysis four elements show their presence as $\mathrm{Ag}$ (51.44 weight \%), $\mathrm{C}(22.45$ weight \%), $\mathrm{Cl}$ (1.18 weight $\%)$ and $\mathrm{O}(22.24$ weight $\%)$ in the synthesized $\mathrm{AgNPs}$ of $5 \mathrm{mM}\left(\mathrm{BMF}_{1: 9)}\right)$ XRD revealed that the crystals nature of synthesized AgNPs were cubic, and TEM results shows that the biosynthesized nanoparticles are agglomerated and irregular shaped in which size ranging from $12 \mathrm{~nm}$ to $38 \mathrm{~nm}$. Synthesized AgNPs were also found to be active for potent antibacterial activity against various pathogenic and harmfull bacterial strains of humans like Pseudomonas Sp. $(19.5 \mathrm{~mm})$, Bacillus cereus $(21 \mathrm{~mm})$ and CoNS (Coagulase Negative Staphylococci) (16.4 mm).Synthesized nanomaterial may be active for efficient clinical applications.
\end{abstract}

Keywords: Green synthesis $\bullet$ Bistorta macrophylla $\bullet$ Polygonaceae $\bullet$ Antimicrobial $\bullet$ SEM-EDX

\section{Introduction}

Nanoparticles can be defined as sub nano sized colloidal structures with particles size between 1 to $100 \mathrm{~nm}$ which is rapidly emerging stream nanotechnology (Vyas and Khar, 2002; Sati et.al., 2020a) and shows unique properties and application of nanomaterials. The metal nanoparticles like silver, zinc oxide, gold etc. have several applicationsviz. optics, coating, nanomedicines, super capacitor bio-labeling, batteries, and catalytic agent in reactions, antibacterial materials, chemically stable materials and good electrical conductors (Sharma et.al., 2009; Zargar et.al., 2014). Green nanotechnology research pathways is an interesting platformfor the preparation of nano structured particles as well as nanocomposites (Baskaralingam et.al., 2011).Green root synthesisis an eco-friendly, nontoxicand safe technology for the formation of nano sized materials in the field of material sciences which includes the formation of 
nanoparticles by metal reduction (silver) process in the presence of various phyto-constituents which are responsible for the reduction. Effective synthesis of metal nanoparticles (MNPs) is the requirement of present scenario, because synthesized MNPs can be active material for many biological activities (Bunghez et.al., 2011; Thirumurugan,2010).

The plant species Bistorta macrophylla (Polygonum macrophyllum) belongs to family Polygonaceae, is native to mountain regions of West Bengal, Tibet, Bhutan, South China, Pakistan and North India (Kashmir, Himachal, Uttarakhand, Valley of flower, Tungnath Himalaya). Bistorta macrophyllais a perennial, small, glabrous herb of Tungnath Himalaya. It is also known as kukhri, kutki in locality. The plant has a height upto $10-25 \mathrm{~cm}$ long with thick rootstock and long radical leaves at an altitude of 3000-4200 meters (Gaur,1999), which can be identified by color of flower i.e. dark red purple color.

\begin{tabular}{|ll|}
\hline $\begin{array}{l}\text { Plant Name } \quad: \\
\text { Bistortamacrophylla }\end{array}$ & $\begin{array}{l}\text { Family : } \\
\text { Polygonaceae }\end{array}$ \\
Locies : B. macrophylla & $\begin{array}{l}\text { Order : } \\
\text { Caryophyllales } \\
\text { Habitat : Alpine } \\
\text { herbs }\end{array}$ \\
Taxonomy $\quad$ Kukhri & Longradical leaves, dark pink \\
seed like flowers.
\end{tabular}

This plant is native from harsh climatic conditions so it can tolerate such harsh temperature. In the phyto-chemical screening of acetone, methanolic, and aqueous extract of B.macrophylla, the presence of glycosides, epicatechin-5-O-beta-Dglucopyranoside, D-glucopyranoside, chlorogenic acid and gallic acid, tannin $(67.96 \mathrm{~g} / \mathrm{Kg})$, saponin (Zhang et.al., 2008) and many compounds have been reported. Phenol contents are highest constituent $(98.12 \mathrm{~g} / \mathrm{Kg})$ in flowers of $P$. macrophyllum. Significant presence of phenol is responsible for protein precipitation in $P$. macrophyllum (Wang et.al., 2004). Selected plant has severalantioxidant properties and potent antimicrobial activity which may be helpful in generating uncommon compound for the development of novel antibacterial agents by nanoparticles synthesis (Kirtikar and Basu, 2006), which may fight against various human pathogens.

\section{Materials and Methods}

The flowers (Fig.1) of B.macrophylla (Kukhri) was collected from Tungnath Himalaya region of Garhwal, Uttarakhand and identified by Taxonomist, Department of Botany HNB Garhwal University Srinagar Garhwal, where the voucher specimens (GUH 6894) was deposited (Gaur, 1999).
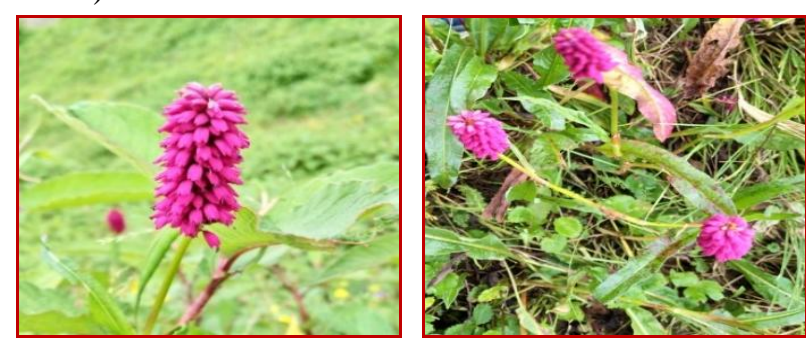

Fig.1: Flowers of Bistorta macrophylla (BMF) Green Synthesis of Silver Nanoparticles

In green approach synthesis, flowers of B.macrophylla had been used for the synthesis of AgNPs. First of all flowers of selected plant were dried in shade for 12-15 days, and thenthe well dried flowers of B.macrophylla were crushed in mixer grinder.For the preparation of flowers extract, we took 5 gram powder of dried flowers in $100 \mathrm{ml}$ deionised water in a round bottom flask and put it on heating mental at $70-80^{\circ} \mathrm{C}$ for $30 \mathrm{~min}$. Resultant flowers extract was filtered two times for removal of contaminants.

Freshly prepared flowers extract added into $\mathrm{AgNO}_{3}$ (Sigma Aldrich, Germany) solution of 5 milli molar concentrations in ratio 1:9, (Bartwal et 
al. 2020). The resulting metal nanoparticles (MNPs) washed two times using deionised water and dry in shade at room temperature (Bartwal et al. 2020, Sati et.al.,2020b).Then synthesized samples of AgNPs were kept for further analysis.

\section{Characterization techniques}

Prepared AgNPs were characterized by several techniques viz.Visual examination, UV spectroscopy,SEM-EDX, XRD and TEM to definevarious parameters of nanoparticles like shape,size, morphology, composition, etc.UVdatawere taken by Double beam spectrophotometer model 3375 (Electronics India), XRD measurements of prepared sample was taken, at room temperature, by an X- ray diffractometer (PANalytical, X'PERT PRO), using $\mathrm{Cu} \mathrm{K} \alpha 1$ radiation of wavelength 1.5405980 $\AA$, in a broad range of $2 \theta\left(20^{\circ}\right.$ to $\left.70^{\circ}\right)$ at a scanning rate of $6^{\circ} / \mathrm{min}$. Surface morphology and grain size of the prepared sample was studied using a SEM (CARL ZEISS, MA15/EVO18), and TEM was taken at HV 120kV (Sati et.al.,2020; Bartwal et al. 2020).

\section{Antimicrobial activity}

To analyse the antimicrobial activity of synthesised AgNPs against the human pathogenic bacteria viz. Psudomonas, Bacillus cereusand CoNS (Coagulase Negative Staphylococci), the well diffusion method (Sati et al. 2020) was employed. AgNPs were dissolved in DMSO. Incubation of petri plates was done at $37^{\circ} \mathrm{C}$ for 24 hours and by measuring the zone of inhibition around the well, antimicrobial activity was determined. The antibacterial effect of synthesised AgNPs was recorded by the measurement of inhibited zone around the well (Sharma et.al., 2009; Kour et.al. 2018; Paudel et.al., 2018).

\section{Results and Discussion}

Visual examination: The preliminary examination of prepared AgNPs was confirmed on the basis of change in color of solutions. The colorchange examination of mix solution of
B.macrrophylla flowers (BMF) and $\mathrm{AgNO}_{3}$ was observed with respect to time (Bartwal et.al., 2020).

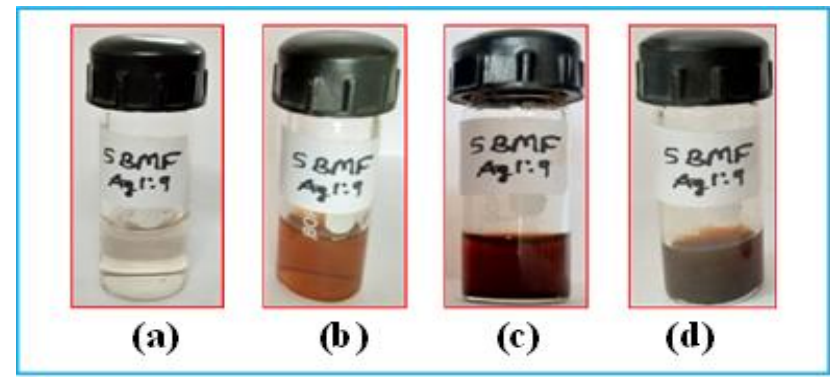

Fig.2: Color change observationat different time intervals (in hours) (a) $\mathrm{t}=0$; (b) $\mathrm{t}=18$; (c) $\mathrm{t}=42$; (d) $\mathrm{t}=66$.

On addition of $B$. macrrophylla flowers extract to $\mathrm{AgNO}_{3}$ solution, color of entire solution system had been changed from whitish yellow to brown red followed by dirty green color (see Fig.2), which exhibit the formation of AgNPs i.e. $\mathrm{Ag}^{+}$ ions have been converted to elemental $\mathrm{Ag}^{0}$ in reaction medium having the size of nano structure range. Obtained results were found similar and were in-accordance to results performed by other researchers (Bartwal et.al., 2020; Bagyalakshmi and and Haritha, 2017).

\section{UV Analysis}

UV analysis shows the formation and completion of formation of AgNPs. AgNPs formation takes place due to surface plasmon resonance (SPR) absorption band due to the combined vibrations of electrons of MNPs in resonance with light wave. AgNPs are known to exhibit UV peakin the range of 451-454 nm (Bartwal et.al.,2020; Bagyalakshmi and and Haritha, 2017).

The absorption peak of synthesized AgNPs were observed at $451 \mathrm{~nm}$ for $5 \mathrm{mM}\left(\mathrm{BMF}_{1: 9}\right)$, for flowers of B. macrophylla (Fig.3). 

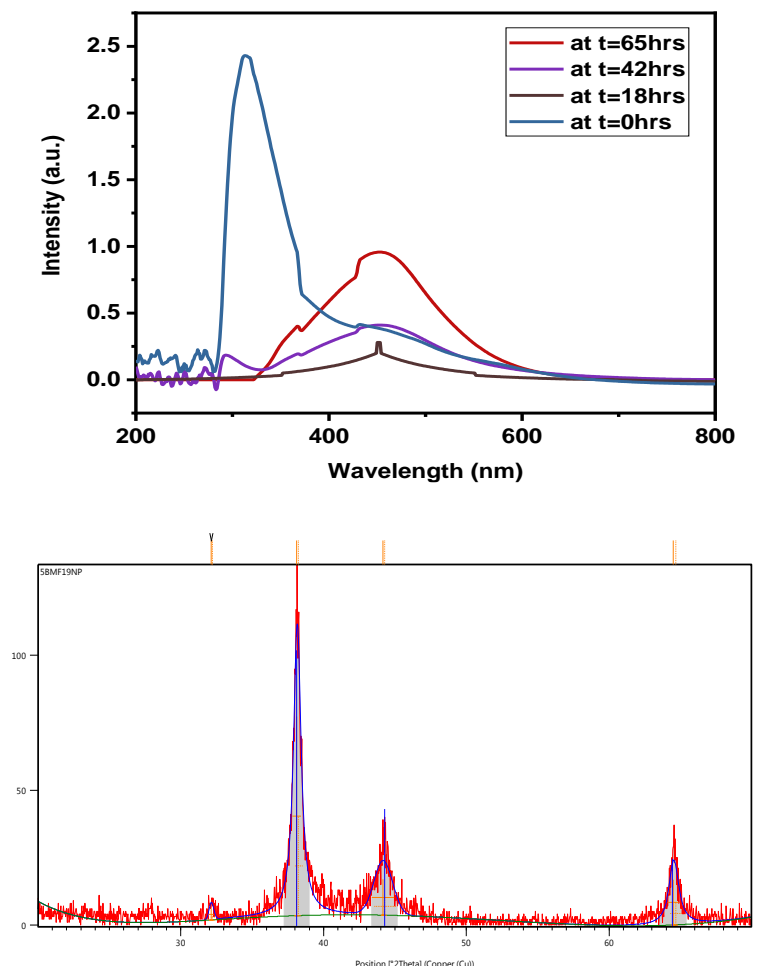

Fig. 3: UV graph of AgNPs of $5 \mathrm{BMF}_{1: 9}$ Fig.4: XRD graph at different intervals XRD Analysis

Fig.4 indicated the diffraction pattern of AgNPs which shows peaks corresponding to elemental Ag (XRD Ag score 81\%). XRD peak $2 \theta$ values observed at $38.117^{\circ}, 44.279^{\circ}$ and $64.428^{\circ}$, with crystalline planes of silver (111), (200) and (220), respectively. The obtained results explain that the produced AgNPs are of $84.260 \AA$ crystal size with cubic crystalline phase, for which the lattice parameteris ' $a$ ' $=4.0862 \AA$ (Sati et.al., 2020a; Bartwal et.al., 2020; Bagyalakshmi and and Haritha, 2017).

\section{SEM-EDX Analysis}

The SEM is convenient for inspection of grain or cluster structure of synthesized nano material AgNPs. It produces 3D appearing Images of micro structural features for observing surface morphology. The prepared AgNPs nanocomposition of $5 \mathrm{BMF}_{1: 9}$ average grain size was $22.16 \mu \mathrm{m}$ (Sati et.al., 2020a, 2020b), some clusters exceeds more than $40 \mu \mathrm{m}$ with agglomerated and smooth surfaces (see Fig.6).
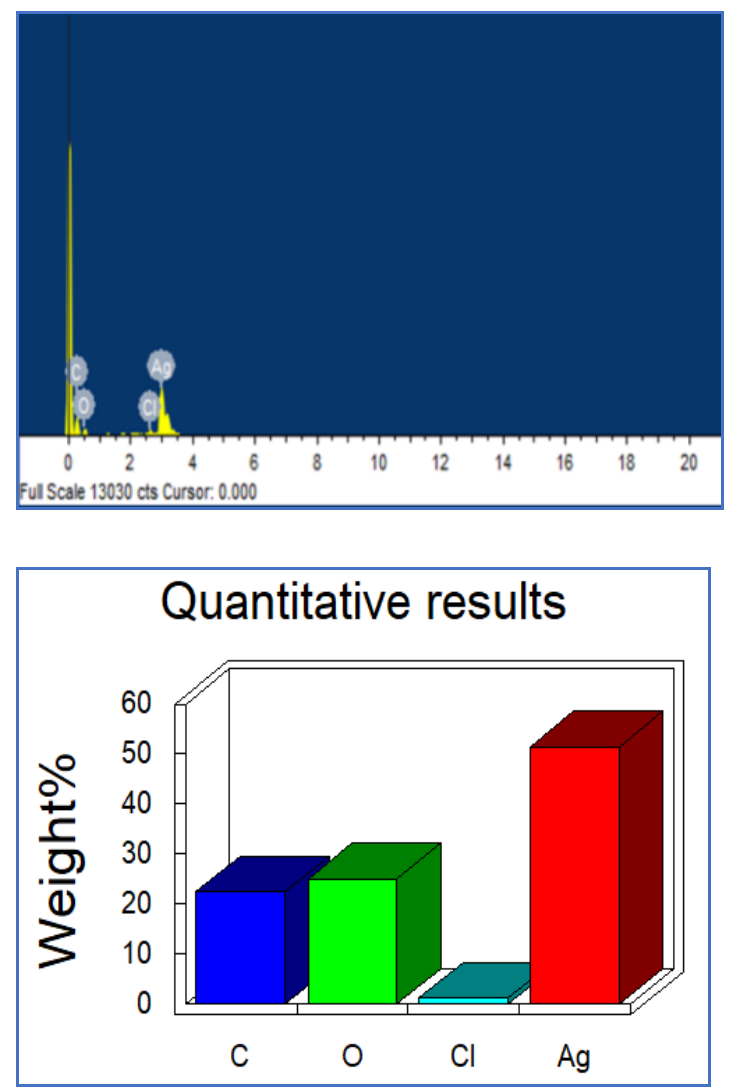

Fig.5: EDX Graph with bar diagram

In the EDX analysis, result of synthesized AgNPs of $5 \mathrm{BMF}_{1: 9}$ observed that the significant $\mathrm{Ag}$ was present with $51.44 \%$ of weight percentage with some chlorine $(1.18 \%)$, oxygen $(24.93 \%)$ and carbon $(22.45 \%)[2,12]$ contaminantsin the synthesized nanoparticles (see Fig.5). 


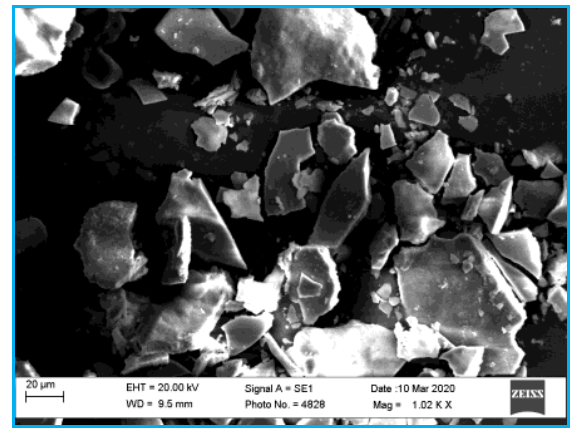

Fig.6: SEM Images
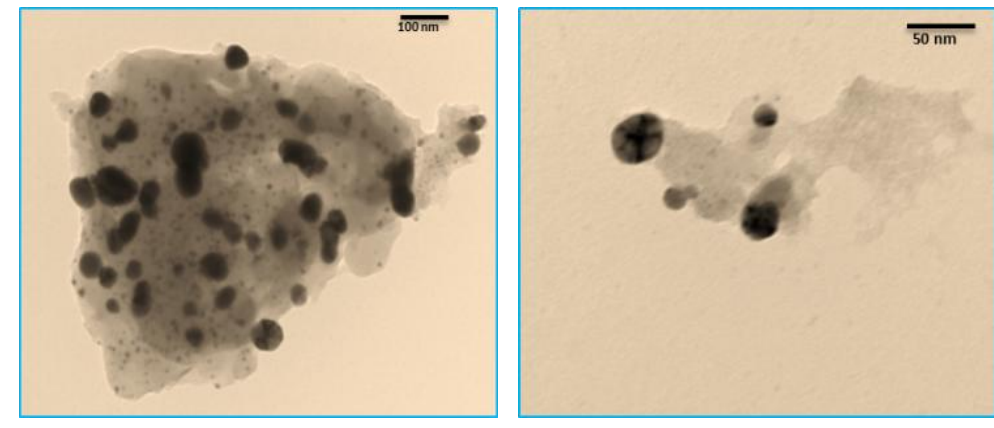

Fig.7: TEM Images

\section{TEM Analysis}

The surface morphology and size of the produced MNPs were alsodeterminedthrough TEM which is a convenient tool, in which the average particle size was calculated by taking theaverage size ofsmallest and largestparticles in the image.In the TEM analysis of AgNPs of $5 \mathrm{BMF}_{1: 9}$, average grain size have been observed in range of $12 \mathrm{~nm}$ to $38 \mathrm{~nm}$ (Bartwal et.al., 2020; Bagyalakshmi and and Haritha, 2017), while some grains size exceeds upto $40 \mathrm{~nm}$ (Fig.7).

\section{Antimicrobial activity}

Table 5.1: Antimicrobialactivity of AgNPs

\begin{tabular}{llcc}
\hline S. No. & Organisms & $\begin{array}{c}\text { Zone of inhibition } \\
(\mathbf{m m})\end{array}$ & $\begin{array}{c}\text { Positive Control } \\
\text { (Streptomycin-25 } \boldsymbol{\mu g} / \mathbf{m l})\end{array}$ \\
\hline 1. & Bacillus cereus & 21 & 22.6 \\
2. & Psudomonas & 19.5 & 21 \\
3. & CoNS & 16.4 & 20 \\
\hline
\end{tabular}

\section{Conclusion}

The present research work focused on the synthesis of MNPs (AgNPs) using B.macrophyllaflowers (BMF) extract via green approach of metal reduction process. The phytochemical organic compounds present in the flowers extract of $B$. macrophylla act as a strong bio-reducing and stabilizing agent during the synthesis of AgNPs. Furthermore, the AgNPs production is also confirmed by different
The synthesized AgNPs from plant extracts showed remarkable antibacterial activity. The bio capped AgNPs obtained from Bistortamacrophyllaflowers showed very good antimicrobial activity (Table 5.1) against Bacillus cereus $(21 \mathrm{~mm})$, Psudomonas $(19.5 \mathrm{~mm})$ and $\operatorname{CoNS}(20.5 \mathrm{~mm})$. It was found that green synthesized AgNPs showed clear zone of inhibition. Here the positive Control was Streptomycin $25 \mu \mathrm{g} / \mathrm{ml}$ (Sharma et.al., 2009; Kour et.al. 2018; Paudel et.al., 2018). spectroscopic techniques. UV analysis shows theabsorption maximapeak at $451 \mathrm{~nm}$ for $5 \mathrm{mM}$

$\left(\mathrm{BMF}_{1: 9}\right)$ for flowers of $B$. macrophylla, which is confirmation of AgNPs formation. XRD confirms that the synthesized nanoparticles exhibit cubiccrystalline structure with average crystal size of $84.260 \AA$ A.SEM image shows the agglomerated particlesof irregular shapes. TEM analysis confirms the average grain sizes of AgNPs were found in the range $12 \mathrm{~nm}$ to $38 \mathrm{~nm}$ with spherical smooth morphology.These nanoparticles also 
showed potent antimicrobial activity against the human pathogenic bacterial strains. Synthesis of silver NPs based of green chemistry principlesis cost effective method which may be used as an alternateof chemical synthesis methods. Synthesized nanomaterial may be useful in pharma industries as development of antimicrobial emulsions, creams and in clinical applications.

\section{Acknowledgement}

Authors are thankful to Dept. of USIC (SEMEDX, XRD), and Rahul Thakur, Dept. of Biotechnology(for antimicrobial activity), HNB Garhwal University for providing data and activity reports of samples.

\section{Conflict of interest}

There is no conflict of interest. This research work is not funded by any funding agencies.

\section{References}

Bagyalakshmi J and Haritha H (2017). Green Synthesis and Characterization of Silver Nanoparticles Using Pterocarpus marsupium and Assessment of its In vitro Antidiabetic Activity; Amer. J Adv. Drug Deliv,.., (3):118-130.

Bartwal AS, Sumitand Sati SC (2020). Biosynthesis of silver nanoparticles from flowers of Rhododenderon campanulatum tree of Tungnath Himalaya; Appl. Innov. Res., ; 2:39-43

Baskaralingam V, Sargunar CG, Lin YC and Chen JC (2012). Green synthesis of silver nanoparticles through Calotropis gigantea leaf extracts and evaluation of antibacterial activity against Vibrio alginolyticus; Nanotech. Dev., 2(1):12-16.

Bunghez IR, Ghiurea M, Faraon V and Ion RM (2011). Green synthesis of silver nanoparticles obtained from plant extracts and their antimicrobial activities; $J$ Optoelect. Adv. Mater., 13(7):870-873.

Gaur RD (1999). Flora of the District Garhwal North West Himalaya (With Ethnobotanical Notes); Trans Media Srinagar (Garhwal); I-edition; 1:133.

Kaur G, Tripathi PK, Sati SC and Mir MA(2018). Synthesis of Silver nanoparticles using leaves extract: Characterization Ficus palmata and evaluation for its Antimicrobial and Antioxidant activities; Asian J. Pharm Pharmacol;4:192-198.

Kirtikar KR and Basu BD (2006).Indian Medicinal Plants; Int. Book Distr., 2: 8421592.

Paudel A, Panthee S, Shakya S, Amatya S, Shrestha TM and Amatya MP (2011). Phytochemical and antibacterial properties of Rhododendron campanulatum from Nepal; Asian J Trad. Med., 6(6):252-258.

Sati SC, Kour G, Bartwal AS and Sati MD (2020). Biosynthesis of Metal Nanoparticles from Leaves of Ficus palmate and Evaluation of Their Anti-inflammatory and Antidiabetic Activities; Bioche; 59(33): 30193025.

Sati SC, Bartwal Sumit \& Agarwal AK (2020). Green synthesis of silver nanoparticles from Citrus medica peels and determination of its antioxidant activity; Appl. Innov. Res.,; 2:56-60.

Sharma VK, Yngard RA and Lin Y. (2009). Silver nanoparticles: green synthesis and their antimicrobial activities; Adv. Coll. Interf. Sci., 145(1-2):83-96.

Thirumurugan A, Ganesh RJ, Akila S, Tomy NA and Meruvu H (2010). J Pharm Res; 3: 2510-2511.

Vyas SP and Khar RK (2002). Targeted and controlled drug delivery novel carrier systems; 331-379. 
J. Mountain Res. P-ISSN: 0974-3030, E-ISSN: 2582-5011

Vol. 16(1), (2021), 161-167

DOI: https://doi.org/10.51220/jmr.v16il.16

Wang S, Wang D andFeng S (2004). Studies on chemical constituents from Polygonum macrophyllum; J Chin., Med. Mater., 7(6):411-413.

Zargar M, Shameli K, Najafi GR and Farahani F (2014). Plant mediated green biosynthesis of silver nanoparticles using Vitexnegundo L. extract; $J$ Ind. Eng. Chem; 20(6):4169-4175.

Zhang X, Long RJ, Dan RF andDing XZ (2008). Analysis of phenols content of three species of Polygonum in alpine meadows; J Gansu Agr. Uni., 01.

$* * * * * * *$ 